\title{
Major depressive disorder is associated with subsequent adult-onset asthma: a population-based cohort study - CORRIGENDUM
}

\author{
T-C. Shen, C-L. Lin, C.H. Liao, C-C. Wei, F-C. Sung and C-H Kao
}

DOI: http://dx.doi.org/10.1017/S2045796016000664 Published online: 19 September 2016

First published online 18 October 2018

In the above mentioned article the title was incorrect. This has now been amended in the published article.

The authors apologise for this error.

\section{Reference}

Shen T.-C., Lin C.-L., Liao C.H., Wei C.-C., Sung F.-C. and Kao C.-H. (2016) 'Major depressive disorder is associated with subsequent adult-onset asthma: a population-based cohort study (Revision 2)', Epidemiology and Psychiatric Sciences, pp. 1-8. doi: 10.1017/S2045796016000664. 